\title{
Características fermentativas na ensilagem de cana-de-açúcar com maniçoba
}

\author{
Fermentative characteristics in sugarcane silage with maniçoba
}

\author{
Francisco Allan Leandro de Carvalho ${ }^{\mathrm{I}}$ Mário Adriano Ávila Queiroz ${ }^{\mathrm{I}^{*}}$ José Gledyson da Silva $^{\mathrm{I}}$ \\ Tadeu Vinhas Voltolini ${ }^{I I}$
}

\section{RESUMO}

A utilização da silagem de cana-de-açúcar apresenta benefícios que têm despertado interesse de produtores e pesquisadores. No entanto, algumas limitações, principalmente relacionadas ao seu padrão de fermentação, têm constituído grande desafio para utilização desta forrageira. Com objetivo de avaliar a inclusão de maniçoba sobre as características fermentativas na silagem de cana-de-açúcar, foi elaborado experimento em delineamento inteiramente casualizado com quatro tratamentos (níveis de inclusão: 0, 20, 30 e 40\%) e seis repetições. Após 90 dias do fechamento dos silos, foram determinadas as perdas na forma de gases, perda total e recuperação de matéria seca e produção de efluentes. Os silos então foram abertos e obtido o extrato aquoso das silagens, foram determinados os teores dos ácidos orgânicos (acético, butírico, lático e propiônico), etanol, $\mathrm{N}-\mathrm{NH}_{3}, \mathrm{NT}$ e valores de $\mathrm{pH}$. À medida que se aumentou o nível de inclusão de maniçoba, foi observada redução de $67 \%$ nas perdas por gases e de $23,3 \%$ na produção de efluente, enquanto a concentração de etanol foi reduzida de 25,6 a 2,7\%. As máximas concentrações de ácido lático $(2,4 \%)$, acético $(2,2 \%)$ e propiônico $(0,03 \%)$ foram encontradas em silagens contendo $40 \%$ de maniçoba, enquanto que, para o ácido butírico, decresceu linearmente. Em todas as silagens, o pH encontrado mostrou-se adequado ao processo de ensilagem (variação de 3,4 a 3,7). O maior nível de inclusão de maniçoba em silagens de cana-de-açúcar melhora a fermentação das silagens e reduz as perdas fermentativas.

Palavras-chave: perdas fermentativas, efluente, fermentação alcoolica.

\section{ABSTRACT}

The use of silage sugar cane has a benefit that has aroused the interest of producers and researchers. However, some limitations mainly related to its fermentation pattern, has become the challenge for forage use. To evaluate the inclusion of maniçoba on silage fermentation characteristics of sugar cane, it was prepared an experiment in a completely randomized design with four treatments (inclusion levels: 0, 20, 30 and 40\%) and six replications. After 90 days of the silos closing o were resoluted losses in the form of gases, total loss and recovery of dry matter production and effluent. The silos were opened and then obtained the aqueous extract of the silages, determined levels of organic acids (acetic, butyric, lactic and propionic), ethanol, NH3-N, NT and pH values. As the level of inclusion of maniçoba was increased, it was observed a $67 \%$ reduction in the losses of gases and $23.3 \%$ in the effluent production, while the ethanol concentration was reduced from 25.6 to $2.7 \%$. The maximum concentration of lactic acid (2.4\%), acetic acid $(2.2 \%)$ and propionic $(0.03 \%)$ were found in silages containing $40 \%$ of maniçoba, while for butyric acid it decreased linearly. In all silages the $\mathrm{pH}$ found was adequate to silage (range 3.4 to 3.7). The highest level of maniçoba inclusion in sugar cane silages improves the fermentation of the silage and reduces fermentation losses.

Key words: fermentative losses, effluent, alcoholic fermentation.

\section{INTRODUÇÃO}

A silagem de cana-de-açúcar merece destaque pelos teores de matéria seca, carboidratos solúveis e capacidade tampão, além disso, elimina a necessidade de corte diário, constituindo grande benefício em operacionalidade e, sobretudo, pela alta produtividade de massa verde, baixo custo por unidade de matéria seca e melhor valor nutritivo no período seco do ano, quando se observa escassez de forragem (SCHMIDT, 2006; REZENDE et al., 2011).

IPrograma de Pós-graduação em Ciência Animal, Universidade Federal do Vale do São Francisco (UNIVASF), Rodovia BR 407, km 12, lote 543, Projeto de Irrigação Nilo Coelho, s/n, zona rural, 56310-770, Petrolina, PE, Brasil. E-mail: mario.queiroz@univasf.edu.br. *Autor para correspondência.

"Embrapa Semiárido, Petrolina, PE, Brasil. 
Apesar do alto potencial produtivo como recurso forrageiro, de acordo com SCHMIDT (2006), a cana-de-açúcar possui algumas limitações do ponto de vista nutricional, tais como os baixos teores de proteínas e minerais. Além disso, as perdas fermentativas e a ocorrência da fermentação alcoolica constituem grande desafio para utilização da cana-deaçúcar na forma de silagem.

Silagem de cana-de-açúcar apresenta padrão de fermentação caracterizado pela alta produção de etanol e elevado desaparecimento de carboidratos solúveis, o que pode ocasionar perdas de matéria seca, redução no valor nutritivo e elevada produção de efluente (CAVALI et al., 2010). As perdas de matéria seca elevam proporcionalmente os constituintes fibrosos, reduzindo consequentemente a digestibilidade da matéria seca. A presença de etanol, por sua vez, pode reduzir o consumo voluntário de silagem pelos animais e aumentar as perdas em decorrência de sua volatilização.

Várias pesquisas têm sido realizadas com objetivo de controlar perdas nas silagens de cana (AMARAL et al., 2009; PEDROSO et al., 2011), a maioria delas utilizam, para isso, aditivos químicos e/ou microbianos. No entanto, são escassos na literatura trabalhos que avaliam efeito associativo entre forrageiras sobre as perdas fermentativas na silagem da cana. Há interesse em associar plantas forrageiras visando melhoria da qualidade das silagens pela adição de forrageiras com elevado valor bromatológico disponíveis em regiões semiáridas.

Nesse contexto, a maniçoba apresenta alto potencial de exploração, devido sua composição químico-bromatológica favorável, visando melhor aproveitamento dos recursos forrageiros disponíveis. Objetivou-se avaliar os efeitos de níveis de inclusão $(0,20,30$ e $40 \%)$ de maniçoba na ensilagem de canade-açúcar sobre o padrão de fermentação.

\section{MATERIAL E MÉTODOS}

Para confecção das silagens, foram utilizados 24 silos constituídos de baldes plásticos com 25 litros de capacidade, com $2 \mathrm{~kg}$ de areia seca no fundo, tela fina de plástico e de tecido de algodão sobrepostos e tampas dotadas de válvulas do tipo Bunsen, para escape dos gases e quantificação gravimétrica destes.

As forrageiras utilizadas foram colhidas manualmente com idades de dezoito e oito meses de idade para cana-de-açúcar cv. 'RB 943206' e maniçoba - Manihot pseudoglaziovii, respectivamente, trituradas separadamente em forrageira estacionaria com tamanho de partícula variando de 2 a $3 \mathrm{~cm} \mathrm{e}$ compactadas por pisoteio, objetivando alcançar densidade mínima de $600 \mathrm{~kg} \mathrm{~m}^{-3}$ de forragem fresca, obedecendo às devidas proporções $(0,20,30$ e $40 \%$ de maniçoba em substituição à cana-de-açúcar). Amostras de cada forragem fresca foram coletadas para determinação de matéria seca, matéria orgânica, nitrogênio total (AOAC, 1995) FDN e FDA (VAN SOEST et al., 1991), obtendo-se valores de 29,0\%; $98,3 \% ; 0,34 \% ; 41,0 \%$ e $30,8 \%$ para cana-de-açúcar e $33,5 \% ; 93,9 \% ; 1,98 \% ; 45,0 \%$ e $28,43 \%$ para maniçoba, respectivamente. Logo após, os silos foram devidamente vedados com auxílio de fita adesiva, pesados para mensuração da densidade e mantidos em local protegido à temperatura ambiente.

Decorridos 90 dias, os silos foram abertos e submetidos a avaliações de perda por gases, obtida com base na pesagem dos silos no fechamento e na abertura, perda de matéria seca, determinada pela diferença entre o peso bruto de MS inicial e final dos silos e produção de efluente, calculada pela diferença de peso do conjunto silo+areia+tela+tecido na abertura (após retirar a forragem do silo) e no fechamento dos silos, conforme equações descritas por SIQUEIRA et al. (2007):

$\mathrm{PE}=(\mathrm{PSAF}-\mathrm{PSAI}) / \mathrm{MNI} \times 1000$, em que: $\mathrm{PE}=$ produção de efluente $(\mathrm{kg}$ de efluente $/ \mathrm{t}$ de matéria verde ensilada); PSAF = peso do conjunto silo, areia, tela e tecido após a abertura $(\mathrm{kg})$; PSAI $=$ peso do conjunto silo, areia, tela e tecido antes da ensilagem $(\mathrm{kg})$; e $\mathrm{MNI}=$ quantidade de forragem ensilada $(\mathrm{kg})$. $\mathrm{PG}=(\mathrm{PSI}-\mathrm{PSF}) / \mathrm{MSI} \times 100$, em que $\mathrm{PG}=$ perda por gases $(\%$ da MS); PSI = peso do silo no momento da ensilagem $(\mathrm{kg}) ; \mathrm{PSF}=$ peso do silo no momento da abertura (kg); e MSI = matéria seca ensilada (quantidade de forragem em $\mathrm{kg} \times \% \mathrm{MS}$ ). Recuperação de $\mathrm{MS}=(\mathrm{MSi} / \mathrm{MSf}) * 100$, em que: $\mathrm{MSf}=$ quantidade de MS final; $\mathrm{MSi}=$ quantidade de MS inicial.

A perda total de matéria seca foi calculada pela diferença entre os pesos brutos de MS inicial e final dos silos, em relação à quantidade de MS ensilada, descontados o peso do conjunto silo e areia úmida na abertura (SCHMIDT, 2006) e a densidade calculada a partir da massa ensilada da forragem e do volume do silo, sendo expressa em kg de matéria verde por metro cúbico ( $\left.\mathrm{kg} \mathrm{MV} \cdot \mathrm{m}^{-3}\right)$.

O material retirado foi homogeneizado e dele foram colhidas amostras que foram secas em estufa de circulação forçada de ar regulada a $55^{\circ} \mathrm{C}$, durante 72 horas, moídas em moinho tipo Willey, com peneira de $1 \mathrm{~mm}$ e analisadas quanto o teor de matéria seca (MS) e nitrogênio total (NT), de acordo com a AOAC (1995). 
Em prensa hidráulica, foi obtido o extrato das silagens, a partir do qual foi possível a determinação do $\mathrm{pH}$ em potenciômetro digital, etanol, N-NH3 e dos ácidos orgânicos. As concentrações dos ácidos acético, propiónico e butírico e de etanol foram medidas por cromatografia gasosa em cromatógrafo Thermo Scientific ${ }^{\circledR}$, equipado com detector de ionização de chama fixado e injeção automática de amostras. O teor de ácido láctico foi determinado por cromatografia líquida de alta eficiência (HPLC) e o conteúdo de $\mathrm{N}-\mathrm{NH}_{3}$ por colorimetria.

Foi utilizado delineamento inteiramente casualizado com quatro tratamentos (níveis de inclusão: 0, 20, 30 e 40\%) e seis repetições. Os resultados foram analisados pelo programa computacional Statistical Analysis System - SAS (Versão 9.1, 2003), sendo anteriormente verificada a normalidade dos resíduos pelo teste de SHAPIROWILK (PROC UNIVARIATE) e as variâncias comparadas por contrastes ortogonais, com nível de significância de 5\% pelo PROC GLM. Como os níveis não são equidistantes entre os tratamentos, utilizou-se o PROC IMS para gerar os vetores de cada contraste (linear, quadrática e desvio da quadrática). Posteriormente às análises de contrastes, quando significativas, determinaram-se os parâmetros das equações de regressão pelo PROC REG.

\section{RESULTADOS E DISCUSSÃO}

Foi observada elevação dos teores de matéria seca em função do acréscimo de maniçoba nas silagens, atribuída ao fato de o teor de matéria seca dessa forragem ter sido maior que o da cana-de-açúcar antes da ensilagem. Ao adicionar subproduto da agroindústria (raspa de batata) com maior teor de MS na silagem de cana, REZENDE et al. (2009) também verificaram aumento no teor de matéria seca das silagens.

À medida que se aumentou a proporção de maniçoba na silagem de cana-de-açúcar, observouse redução nas perdas fermentativas (Tabela 1), em função do aumento do teor de matéria seca proveniente da maniçoba. A perda na forma de gases variou de 10,7 a $32,5 \%$, assim como a produção de efluente de $18,6 \mathrm{~kg} \mathrm{t}^{-1} \mathrm{MV}$ a $24,2 \mathrm{~kg} \mathrm{t}^{-1} \mathrm{MV}$ que reduziram 67,0 e 23,3\%, respectivamente, entre o nível máximo de inclusão de maniçoba e o tratamento controle (sem maniçoba). De acordo com AMARAL et al. (2009), o efeito do teor de umidade sobre a produção de efluente é amplamente citado na literatura. Reduções nas perdas por gases e efluentes foram reportadas por REZENDE et al. (2009), ao adicionar raspa de batata com maior teor de MS à silagem de cana.
A quantidade de efluente gerada implica a redução do teor de nutrientes solúveis na silagem, que são carreados para o fundo do silo. A reduzida produção de efluentes observada com inclusão de maniçoba pode ser explicada possivelmente pela inibição no crescimento microbiano, em função do aumento no teor de matéria seca.

As perdas por gases e por efluentes foram acompanhadas pela perda total da matéria seca e o nível máximo de inclusão de maniçoba promoveu redução de $63,2 \%$ em relação à silagem sem maniçoba. PEDROSO et al. (2011) observaram valores semelhantes de perdas totais em silagens de cana tratadas com aditvos químicos e inoculante microbiano. Segundo SCHMIDT (2006), a canade-açúcar apresenta, em sua composição, altos teores de carboidratos solúveis e grande população de leveduras epífitas, responsáveis pela indesejada fermentação alcoolica, causando perdas excessivas de MS e de valor nutritivo da forragem.

Comportamento linear crescente foi verificado na recuperação da matéria seca, observando valores de $65,8 \%$ para a silagem sem maniçoba, contra $87,4 \%$, quando acrescido $40 \%$ de maniçoba na ensilagem, o que representou aumento de $24,7 \%$ de recuperação de matéria seca. Quanto à variável densidade, conforme pretendido, não houve diferença $(\mathrm{P}>0,05)$ com a inclusão de maniçoba na silagem de cana $\left(\mathrm{y}=599,79 \mathrm{~kg} \mathrm{MV} \mathrm{m}^{-3}\right)$.

A redução nas perdas fermentativas e o aumento na recuperação da matéria seca da silagem de cana-de-açúcar podem ser atribuídos a redução do teor de água que, por sua vez, altera a pressão osmótica do meio, criando condição menos favorável para o desenvolvimento de leveduras (VAN SOEST, 1994). Adicionalmente, a mudança da população epífita da massa ensilada com inclusão de maniçoba tende a reduzir a população de leveduras que, durante a fermentação, consomem carboidratos solúveis e geram etanol e $\mathrm{CO}_{2}$.

O teor de etanol (Tabela 2) também decresceu com adição de maniçoba, apresentando valores de $25,6 \%$ na silagem exclusivamente de cana contra $2,7 \%$ na silagem com maior inclusão. Isto pode ser explicado principalmente pelo maior teor de matéria seca observado nas silagens com maniçoba, proporcionando redução de $0,55 \%$ de etanol para unidade percentual de maniçoba adicionada. Estes resultados podem ter contribuído para a elevada produção de efluente e perdas por gases na silagem controle.

Durante o processo fermentativo, microrganismos consomem proteínas e carboidratos, podendo gerar vários produtos, como ácidos 
Tabela 1 - Perdas fermentativas, recuperação da matéria seca e densidade de silagens de cana-de-açúcar com maniçoba.

\begin{tabular}{|c|c|c|c|c|c|}
\hline \multirow{2}{*}{ Variáveis } & \multicolumn{4}{|c|}{-Níveis de maniçoba (\%MV)---- } & \multirow{2}{*}{ EPM } \\
\hline & 0 & 20 & 30 & 40 & \\
\hline Matéria seca, $\%$ & 25,2 & 26,6 & 27,3 & 28,5 & 0,44 \\
\hline Perdas por efluente, $\mathrm{kg} \mathrm{t}^{-1} \mathrm{MV}$ & 24,2 & 24,1 & 19,5 & 18,6 & 0,97 \\
\hline Perdas por gases, $\% \mathrm{MS}$ & 32,5 & 22,4 & 14,0 & 10,7 & 0,21 \\
\hline Perda total de matéria seca, $\%$ & 34,2 & 24,3 & 15,6 & 12,6 & 0,16 \\
\hline Recuperação da matéria seca, \% & 65,8 & 75,7 & 84,4 & 87,4 & 0,23 \\
\hline Densidade, $\mathrm{kg} \mathrm{MV} \mathrm{m}^{-3}$ & 593,0 & 599,1 & 608,7 & 598,4 & 3,01 \\
\hline Variáveis & \multicolumn{4}{|c|}{ Equação de regressão } & $\mathrm{R}^{2}$ \\
\hline Matéria seca, \% & \multicolumn{4}{|c|}{$y=25,117+0,079 x$} & 0,62 \\
\hline Perdas por efluente, $\mathrm{kg} \mathrm{t}^{-1} \mathrm{MV}$ & \multicolumn{4}{|c|}{$y=24,985-0,145 x$} & 0,47 \\
\hline Perdas por gases, $\% \mathrm{MS}$ & \multicolumn{4}{|c|}{$y=32,725-0,565 x$} & 0,98 \\
\hline Perda total de matéria seca, $\%$ & \multicolumn{4}{|c|}{$y=34,552-0,567 x$} & 0,98 \\
\hline Recuperação da matéria seca, \% & \multicolumn{4}{|c|}{$y=65,449+0,567 x$} & 0,98 \\
\hline Densidade, $\mathrm{kg} \mathrm{MV} \mathrm{m}^{-3}$ & \multicolumn{4}{|c|}{$y=599,79$} & - \\
\hline
\end{tabular}

$\mathrm{EPM}=$ erro padrão na média; $\mathrm{ER}=$ equação de regressão; $\mathrm{R}^{2}=$ coeficiente de determinação.

orgânicos, etanol, água, ATP e dióxido de carbono. $\mathrm{Na}$ silagem de cana-de-açúcar, a produção de gás carbônico durante a fermentação é bastante significativa e as perdas por gases apresentam alta correlação com a produção de etanol por leveduras (AMARAL et al., 2009). Além de perdas do material ensilado, a presença de etanol pode provocar perdas decorrentes da recusa dos animais.

As silagens de cana apresentaram valor máximo de $\mathrm{pH}$ de 3,7 estimado para o nível $2 \%$ de maniçoba. CAVALI et al. (2010) ressaltaram que, para silagem de cana-de-açúcar, o pH, quando considerado isoladamente, não é um bom indicador de qualidade da fermentação, pois a principal fermentação indesejável na silagem de cana é caracterizada pela ocorrência de leveduras que se desenvolvem mesmo em baixos valores de $\mathrm{pH}$, e o próprio etanol pode agir como inibidor microbiano. Estes autores avaliaram silagens mistas de cana-de-açúcar com capim elefante e encontraram comportamento semelhante para o $\mathrm{pH}$ da silagem de cana sem inoculantes. $\mathrm{O}$ controle de perdas e a produção de etanol devem ser, portanto, o foco na ensilagem de cana-de-açúcar (BERNARDES et al., 2007).

De acordo com VAN SOEST (1994), a rápida queda do $\mathrm{pH}$ e valor final de $\mathrm{pH}$ baixo pode diminuir a população de microrganismos prejudiciais à ensilagem, reduzindo a possibilidade de se obter

Tabela 2 - Valores de pH, nitrogênio amoniacal, nitrogênio total (NT), N-NH3/NT, etanol e ácidos orgânicos (acético, lático, propiônico e butírico) em silagens de cana-de-açúcar com maniçoba.

\begin{tabular}{|c|c|c|c|c|c|c|c|}
\hline \multirow{2}{*}{ Variáveis } & & reis de $n$ & ba (\%) & & \multirow{2}{*}{ EPM } & \multirow{2}{*}{ ER } & \multirow{2}{*}{$\mathrm{R}^{2}$} \\
\hline & 0 & 20 & 30 & 40 & & & \\
\hline $\mathrm{pH}$ & 3,7 & 3,7 & 3,4 & 3,4 & 0,012 & $y=3,67+0,00078 x-0,0002 x^{2}$ & 0,67 \\
\hline Etanol, \% MS & 25,6 & 14,1 & 11,0 & 2,7 & 0,674 & $y=25,72-0,55 x$ & 0,96 \\
\hline Lático, \% MS & 1,7 & 1,3 & 2,1 & 2,4 & 0,137 & $y=1,7-0,03 x+0,0013 x^{2}$ & 0,59 \\
\hline Acético, \% MS & 1,5 & 1,8 & 2,0 & 2,2 & 0,037 & $y=1,53+0,016 x$ & 0,91 \\
\hline Propiônico, \% MS & 0,02 & 0,02 & 0,02 & 0,03 & 0,001 & $y=0,02-0,0007 x+0,00002 x^{2}$ & 0,80 \\
\hline Butírico, \% MS & 0,05 & 0,02 & 0,02 & 0,02 & 0,004 & $y=0,04086-0,00061 x$ & 0,36 \\
\hline NT, \% MS & 0,34 & 0,70 & 0,90 & 1,04 & 0,006 & $y=0,345+0,018 x$ & 0,99 \\
\hline $\mathrm{N}-\mathrm{NH}_{3} \%$ & 0,026 & 0,048 & 0,028 & 0,003 & 0,001 & $y=0,026+0,0025 x-0,00008 x^{2}$ & 0,95 \\
\hline $\mathrm{N}-\mathrm{NH}_{3} / \mathrm{NT}$ & 0,08 & 0,07 & 0,03 & 0,003 & 0,002 & $y=0,084-0,0018 x$ & 0,81 \\
\hline
\end{tabular}

$\mathrm{EPM}=$ erro padrão na média; $\mathrm{ER}=$ equação de regressão; $\mathrm{R}^{2}=$ coeficiente de determinação; $\mathrm{NT}=$ nitrogênio total; $\mathrm{N}-\mathrm{NH}{ }_{3}=$ nitrogênio amoniacal.

Ciência Rural, v.44, n.11, nov, 2014. 
produtos indesejáveis, como ácido butírico, além de diminuir a proteólise e poder de tampão.

Com a adição de maniçoba na silagem de cana, foi observadoefeitoquadráticopara concentrações de ácido lático. De acordo com a equação de regressão ao nível de $11,6 \%$ de maniçoba foi estimado teor mínimo de $1,5 \%$. O maior valor $(2,4 \%)$ foi observado na silagem com $40 \%$ de maniçoba, no entanto, foi inferior aos encontrados por SCHMIDT et al. (2011) 3,63\%; $3,60 \%$ e $4,34 \%$ para silagem controle e aditivada com L. buchneri e L. brevis + Enterococcus faecium $+\boldsymbol{L}$. plantarum, respectivamente. SANTOS et al. (2008) encontraram significante correlação entre $\mathrm{pH}$ e teor de ácido lático nas silagens estudadas, fato que explica comportamento quadrático do $\mathrm{pH}$ obtido neste estudo. As perdas por gases também podem ser influenciadas positivamente pelo teor de ácido lático, uma vez que, no metabolismo de bactérias homofermentativas, a fermentação de glicose com síntese de ácido lático não gera produção de $\mathrm{CO}_{2}$ (LORENZO e KIELY, 2008).

A inclusão de maniçoba na silagem de cana-de-açúcar aumentou os teores de ácido acético com efeito linear crescente e variação de 1,53 a $2,15 \%$ MS entre o tratamento sem maniçoba e aquele com maior nível de inclusão. A presença de ácido acético diminui a produção de etanol, assumindo importante papel antifúngico durante a fermentação da silagem. O aumento na concentração de ácido acético pode ser resultado do metabolismo de bactérias láticas heterofermentativa, tais como $\boldsymbol{L}$. buchneri e L. brevis (OUDE ELFERINK et al. 2001), naturalmente presentes na cana-de-açúcar e que tem seu crescimento favorecido na faixa de $\mathrm{pH}$ observada no presente estudo.

Para silagens de cana-de-açúcar, são esperadas baixas concentrações de ácido propiônico. Os valores observados neste estudo indicaram efeito quadrático apresentando menor valor $(0,014 \%)$ ao nível de $17 \%$ de inclusão de maniçoba, o que possivelmente pode ser explicado pelo teor de ácido lático, que apresentou comportamento semelhante em função dos tratamentos. A produção de ácido propiônico está associada com a conversão de ácido lático a acético e 1,2-propanodiol (OUDEELFERINK et al., 2001), que, por sua vez, é convertido a ácido propiônico e 1-propanol (CARVALHO et al., 2012).

De forma geral, a concentração de ácido butírico em silagens de cana-de-açúcar é considerada baixa (AMARAL et al., 2009) e frequentemente associada à fermentação clostridiana. Efeito linear decrescente foi observado para o teor de ácido butírico, com variação de 0,02 a $0,05 \% \mathrm{MS}$, em decorrência do menor $\mathrm{pH}$ apresentado pela silagem com $40 \%$ de maniçoba. Em condições de baixo $\mathrm{pH}$, a síntese de ácidos por clostridios é interrompida e outros produtos, tais como acetona e butanol, podem ser produzidos (McDONALD et al., 1991).

A maioria dos estudos revistos por ZOPOLLATTO et al. (2009) apresentou valores médios de 0,1\% MS de ácido butírico em silagens de cana-de-açúcar. Entretanto, AMARAL et al. (2009) encontraram concentrações de ácido butírico de 3,1\% em silagem de cana-de-açúcar enriquecida com $1 \%$ de óxido de cálcio e atribuíram esse resultado ao $\mathrm{pH}$ mais elevado da silagem tratada com óxido de cálcio, possibilitando o crescimento de clostridios.

Todas as silagens apresentaram baixos teores de $\mathrm{N}-\mathrm{NH}_{3} \%$ da MS apesar do efeito quadrático observado, além de baixos valores para relação $\mathrm{N}-\mathrm{NH}_{3} / \mathrm{N}$-Total \% da MS, indicando baixa degradação de proteínas durante a ensilagem e eficiência do processo fermentativo. Nas forragens frescas, foram observados teores de nitrogênio total de 0,34 e 1,76\% para cana e maniçoba, respectivamente, e 0,$35 ; 0,70$; 0,90 e $1,04 \%$ para silagens de cana com $0,20,30$ e $40 \%$ de maniçoba, respectivamente, o que pode ter provocado aumento nos valores da relação $\mathrm{N}-\mathrm{NH}_{3} / \mathrm{N}-$ Total observados nesta pesquisa.

Durante a ensilagem, o nitrogênio total pode ser diminuído em função da degradação proteica mediada por microrganismos. O conteúdo de nitrogênio presente sob a forma de amônia $\left(\mathrm{N}-\mathrm{NH}_{3}\right)$ na silagem deve estar presente em baixas concentrações (VAN SOEST, 1994). Em geral, silagens com menos de $10 \%$ de N-NH3/N-Total apresentam fermentação considerada eficiente para a conservação do material ensilado, enquanto valores crescentes de N-NH3/NTotal podem ser relacionados à redução gradual desta eficiência (TOMICH, 2003).

\section{CONCLUSÃO}

A inclusão da maniçoba na ensilagem de cana-de-açúcar mostrou-se eficiente em reduzir a fermentação alcoolica da silagem. Melhorou a qualidade fermentativa, alterou positivamente o padrão de fermentação, reduzindo perdas de matéria seca, perdas por gases e produção de efluente.

\section{REFERÊNCIAS}

AMARAL, R.C. et al. Cana-de-açúcar ensilada com ou sem aditivos químicos: fermentação e composição química. Revista Brasileira de Zootecnia, v.38, n.8, p.1413-1421, 2009. Disponível em: $<$ http://www.scielo.br/scielo.php?script=sci_abstract\&pid=S1516$35982009000800004 \& \operatorname{lng}=e n \& n r m=i s o \& t \operatorname{lng}=p t>$. Acesso em: 04 jun 2013. doi: 10.1590/S1516-35982009000800004. 
AOAC (ASSOCIATION OF OFFICIAL ANALYTICAL CHEMISTS). Official Methods of Analysis. Washington: Association of Offi cial Analytical Chemists, 1995. p. 1141.

BERNARDES, T.F. et al. Avaliação da queima e da adição de milho desintegrado com palha e sabugo na ensilagem de cana-de-açúcar. Revista Brasileira de Zootecnia, v.36, n.2, p.269-275, 2007. Disponível em: <http://www.scielo.br/scielo. php?script=sci_abstract\&pid=S1516-35982007000200001\&lng= en\&nrm=iso\&tlng=pt>. Acesso em: 25 jul. 2013. doi: 10.1590/ S1516-35982007000200001.

CARVALHO, B.F. et al. Effects of propionic acid and Lactobacillus buchneri (UFLA SIL 72) addition on fermentative and microbiological characteristics of sugar cane silage treated with and without calcium oxide. Grass and Forage Science, v.67, n.4, p.462-471, 2012. Disponível em: <http://onlinelibrary.wiley. com/doi/10.1111/j.1365-2494.2012.00863.x/abstract>. Acesso em: ago. 2013. doi: 10.1111/j.1365-2494.2012.00863.x.

CAVALI, J. et al. Mixed sugarcane and elephant grass silages with or without bacterial inoculant. Revista Brasileira de Zootecnia, v.39, n.3, p.462-470, 2010. Disponível em: <http:// www.scielo.br/scielo.php? script=sci_abstract\&pid=S 1516$35982010000300003 \& \operatorname{lng}=e n \& n r m=i s o \& t \operatorname{lng}=p t>$. Acesso em: 24 jul. 2013. doi: 10.1590/S1516-35982010000300003.

LORENZO, B.F.; O'KIELY, P. Alternatives to formic acid as a grass silage additive under two contrasting ensilability conditions. Irish Journal of Agricultural and Food Research, v.47, n.2, p.135-149, 2008. Disponível em: <http://www.teagasc.ie/research/ journalarchives/vol47no2/ijafr3608.pdf>. Acesso em: jun. 2013.

McDONALD, P. et al. The biochemistry of silage. 2.ed. Marlow: Chalcombe, 1991. 340p.

OUDE ELFERINK, S.J.W.H. et al. Anaerobic conversion of lactic acid to acetic acid and 1,2-propanediol by Lactobacillus buchneri. Applied and Environmental Microbiology, v.67, p.125-132, 2001. Disponível em: 〈http://aem.asm.org/content/67/1.toc〉. Acesso em: abr. 2013. doi:10.1128/AEM.67.1.125-132.2001.

PEDROSO, A.F. et al. Aditivos químicos e inoculante bacteriano na ensilagem de cana-de-açúcar: efeitos sobre a fermentação das silagens e o desempenho de garrotes. Revista Brasileira de Zootecnia, v.40, n.6, p.1181-1187, 2011. Disponível em: <http://www.scielo.br/scielo.php?script=sci_abstract\&pid=S1516$35982011000600004 \& \operatorname{lng}=e n \& n r m=i s o \& t \operatorname{lng}=p t>$. Acesso em: 15 dez. 2012. doi: 10.1590/S1516-35982011000600004.

REZENDE, A.V. et al. Qualidade bromatológica das silagens de cana-de-açúcar (Saccharum officinarum L.) aditivadas com raspa de batata. Revista Ciência e Agrotecnologia, v.33, n.1, p.292-297, 2009. Disponível em: <http://www.scielo.br/scielo. php?script=sci_abstract\&pid=S1413-70542009000100040\&lng $=$ en\&nrm=iso\&tlng=pt>. Acesso em: jun. 2013. doi: 10.1590/ S1413-70542009000100040.

REZENDE, A.V. et al. Perdas fermentativas e estabilidade aeróbia de silagens de cana-de-açúcar tratadas com cal virgem e cloreto de sódio. Revista Brasileira de Zootecnia, v.40, n.4, p.739-746, 2011. Disponível em: <http://www.scielo.br/scielo. php?script=sci_abstract\&pid=S1516-35982011000400006\&lng=e $\mathrm{n} \& \mathrm{nrm}=\mathrm{iso} \&$ tlng=pt $>$. Acesso em: 13 abr. 2013. doi: 10.1590/ S1516-35982011000400006.

SANTOS, M. C.; NUSSIO, L. N.; MOURÃO, G. B.; SCHMIDT, P.; MARI, L. J, RIBEIRO, J. L. Influência da utilização de aditivos químicos no perfil da fermentação, no valor nutritivo e nas perdas de silagens de cana-de-açúcar. Revista Brasileira de Zootecnia, v.37, n.9, p.1555-1563, 2008. Disponível em: 〈http://www.scielo.br/ scielo.php?script=sci_arttext\&pid=S1516-35982008000900006 $>$. Acesso em: jun. 2013. doi: 10.1590/S1516-35982008000900006.

SAS INSTITUTE. SAS/STAT: guide for personal computer, version 9.1. Cary, 2003. 235 p.

SCHMIDT, P. Perdas fermentativas na ensilagem, parâmetros digestivos e desempenho de bovinos de corte alimentados com rações contendo silagens de cana-de-açúcar. 2006. 229f. Tese (Doutorado em Agronomia) - Escola Superior de Agricultura "Luiz de Queiroz", Universidade de São Paulo, Piracicaba, SP.

SCHMIDT, P.; ROSSI JUNIOR, P.; JUNGES, D.; DIAS, L. T.; ALMEIDA, R.; MARI, L. J. Novos aditivos microbianos na ensilagem da cana-de-açúcar: composição bromatológica, perdas fermentativas, componentes voláteis e estabilidade aeróbia. Revista Brasileira de Zootecnia, v.40, n.3, p.543-549, 2011. Disponível em: <http://www.scielo.br/scielo.php?script=sci_artte xt\&pid=S1516-35982011000300011>. Acesso em: jun 2013. doi. 10.1590/S1516-35982011000300011.

SIQUEIRA, G.R. et al. Perdas de silagens de cana-de-açúcar tratadas com aditivos químicos e bacterianos. Revista Brasileira de Zootecnia, v.36, n.6, p.2000-2009, 2007 (supl.). Disponível em: <http://www.scielo.br/scielo.php?script=sci_abstract\&pid=S1516$35982007000900008 \& \operatorname{lng}=\mathrm{en} \& n r m=\mathrm{iso} \& \operatorname{lng}=\mathrm{pt}\rangle$. Acesso em: jun 2013. doi: 10.1590/S1516-35982007000900008.

TOMICH, T.R. et al. Características químicas para avaliação do processo fermentativo de silagens: uma proposta para qualificação da fermentação. Corumbá: Embrapa Pantanal, 2003. 20p. (Documentos, 57). Acesso em: 25 jun 2013. Online. Disponível em: <http://www.cpap.embrapa.br/publicacoes/online/ DOC57.pdf>

VAN SOEST, P.J. et al. Methods for dietary fiber, and nonstarch polysaccharides in relation to animal nutrition. Journal Dairy Science, v.74, p.3583-3597, 1991. Disponível em: <http://www. sciencedirect.com/science/article/pii/S0022030291785512>. Acesso em: abr. 2013. doi: 10.3168/jds.S0022-0302(91)78551-2.

VAN SOEST, P.J. Nutritional ecology of the ruminant. 2.ed. New York: Cornell University, 1994. 476p.

ZOPOLLATTO, M. et al. Aditivos microbiológicos em silagens no Brasil: revisão dos aspectos da ensilagem e do desempenho de animais. Revista Brasileira de Zootecnia, v.38, p.170-189, 2009 (Supl.). Disponível em: <http://www.scielo.br/scielo. php?script=sci_abstract\&pid=S1516-35982009001300018\&lng=e $\mathrm{n} \& n \mathrm{~nm}=\mathrm{iso} \& \mathrm{tln} \mathrm{g}=\mathrm{pt}>$. Acesso em jul. 2013. doi: 10.1590/S151635982009001300018 